\title{
Simple and contingent aftereffects of perceived duration in vision and audition
}

\author{
JAMES T. WALKER, ARTHUR L. IRION, and DOUGLAS G. GORDON \\ University of Missouri, St. Louis, Missouri 63121
}

\begin{abstract}
After repeated presentations of a long inspection tone $(800$ or $1,000 \mathrm{msec})$, a test tone of intermediate duration $(600 \mathrm{msec})$ appeared shorter than it would otherwise appear. A short inspection tone ( 200 or $400 \mathrm{msec}$ ) tended to increase the apparent length of the intermediate test tone. Thus, a negative aftereffect of perceived auditory duration occurred, and a similar aftereffect occurred in the visual modality. These aftereffects, each involving a single sensory dimension, are simple aftereffects. The following procedures produced contingent aftereffects of perceived duration. A pair of lights, the first short and the second long, was presented repeatedly during an inspection period. When a pair of test lights of intermediate duration was then presented, the first member of the pair appeared longer in relation to the second. A similar aftereffect occurred in the auditory modality. In these latter aftereffects, the perceived duration of a test light or tone is contingent-dependent-on its temporal order, first or second, within a pair of test stimuli. An experiment designed to test the possibility of cross-modal transfer of contingent aftereffects between audition and vision found no significant cross-modal aftereffects.
\end{abstract}

A simple aftereffect involves a single sensory dimension such as size, orientation, or motion. After inspecting - that is, adapting to-a stimulus at a particular location on a sensory dimension, a test stimulus at some other point on that dimension appears displaced, typically in a direction away from the location of the inspection stimulus. In a visual figural aftereffect, for example, after inspecting a circle of a particular size, the apparent size of a smaller test circle is made to appear smaller yet, and that of a larger test circle is made to appear larger than it would otherwise appear (Köhler \& Wallach, 1944). A great many other simple aftereffects have been found, for example, involving visual and kinesthetic orientation (Day \& Singer, 1964; Gibson \& Radner, 1937), visual motion (Sekuler \& Pantle, 1967), and kinesthetic perception of length and width (Köhler \& Dinnerstein, 1947; Walker, 1978). In the domain of time perception, the presentation of a 4-sec inspection tone resulted in the shortening of the perceived duration of a subsequently presented 2 -sec test tone (Huppert \& Singer, 1967).

The McCollough effect (McCollough, 1965) has come to represent the classic example of a contingent aftereffect. During an inspection period of a few minutes, a horizontal grating of red and black lines and a vertical grating of green and black are presented alternately every few seconds in the same portion of the visual field. A horizontal achromatic test grating then looks greenish, and a vertical achro-

Some of these results were presented at the annual meeting of the Southern Society for Philosophy and Psychology, Louisville, Kentucky, April 17, 1981. matic grating looks reddish. Thus, the perceived color of the test grating is contingent-dependenton its orientation. In the general case, a contingent aftereffect involves two sensory dimensions, and the apparent location of a stimulus object on one of those sensory dimensions becomes contingent on its location on the other. The contingency relationship arises because of the pairing of different levels of the two dimensions during an inspection period.

It is important to note that in the McCollough effect, two complementary color aftereffects occur in the same region of the visual system. Thus, the McCollough effect and contingent aftereffects in general differ greatly from conventional afterimages and other simple aftereffects, in which a single aftereffect in a single direction occurs in a particular region of a sensory system. The distinction drawn here between simple and contingent aftereffects follows the definitions of Mayhew and Anstis (1972). Numerous contingent aftereffects have been found in the visual modality involving many pairs of sensory dimensions such as color, orientation, spatial frequency, visual texture, and motion (e.g., Favreau, Emerson, \& Corballis, 1972; Held \& Shattuck, 1971; Hepler, 1968; Leppman, 1973; Skowbo, Timney, Gentry, \& Morant, 1975; Walker, 1972). A few contingent aftereffects have been demonstrated in the tactual-kinesthetic modality involving the dimensions of length, width, and orientation (e.g., Walker, 1978).

Two contingent aftereffects of perceived duration have been found in the auditory modality-the first contingent aftereffects to be demonstrated in the domain of time perception (Walker \& Irion, 1979). 
After listening to a series of low-pitched inspection tones of long duration $(600 \mathrm{~Hz}, 600 \mathrm{msec}$ ) alternating with high-pitched short tones $(900 \mathrm{~Hz}, 200 \mathrm{msec})$, a high test tone of intermediate duration $(400 \mathrm{msec})$ then sounded longer than a low test tone of equal length. Thus, the perceived duration of a test tone was contingent on its pitch. To produce the second contingent aftereffect of perceived duration, a pair of short and long inspection tones of the same frequency, having durations of 200 and $1,000 \mathrm{msec}$, was presented repeatedly in the same order-the short tone first, and the long tone second. Within each pair of inspection tones, the short and long tones were separated by silent intervals of $400 \mathrm{msec}$, and successive presentations of the tone pairs were separated by silent intervals of 1,400 msec. When a pair of test tones of equal and intermediate length $(400 \mathrm{msec})$ was then presented, the first test tone sounded longer than the second. Here, the perceived duration of a test tone was contingent on its temporal order-first or second-within a pair of tones.

In the present study, Experiment 1 demonstrated a simple visual aftereffect of perceived duration, a new aftereffect in the visual modality. The measurement procedure in that experiment was a method of kinesthetic reproduction (for discussions of methodology and other issues in time perception, see Allan, 1979; Fraisse, 1963; Woodrow, 1951). For comparison, a simple auditory aftereffect of perceived duration was produced in Experiment 2 using the same measurement procedure. Experiment 3 demonstrated a new contingent aftereffect in the visual modality, an aftereffect of perceived duration contingent on temporal order, and Experiment 4 demonstrated an analogous aftereffect in the auditory modality. Those last two experiments both used a reproduction method, a procedure very different from the magnitude estimation method used in the earlier study of contingent aftereffects of perceived duration described above (Walker \& Irion, 1979). Experiment 5 provided a test of cross-modal transfer of contingent aftereffects between audition and vision. No significant cross-modal aftereffects were found.

\section{EXPERIMENT 1: SIMPLE AFTEREFFECTS IN VISION}

This experiment was designed to measure the effects of inspection lights, ranging in length from 200 to $1,000 \mathrm{msec}$, on the perceived duration of a $600-\mathrm{msec}$ test light. Those durations are close to the interval of indifference, that time interval that is neither undernor overestimated, and are also within the range in which the Weber ratio is minimal (Fraisse, 1963; Woodrow, 1951).

\section{Method}

Subjects. Fifteen male undergraduate psychology students at the University of Missouri-St. Louis participated as a course re- quirement. All subjects claimed to be free of any serious visual problem. For the reasons described below in the Procedure section, five potential subjects were replaced.

Apparatus. The visual stimulus was a neon light behind a $15 \times$ $20 \mathrm{~mm}$ rectangular Fresnel lens having a surface luminance of about $90 \mathrm{~mL}$. The light was mounted approximately at eye level in the center of a $23 \times 28 \mathrm{~cm}$ vertical black surface at a viewing distance of $1.4 \mathrm{~m}$. The experiment was conducted in an acoustic chamber about $1.8 \times 1.9 \times 2.0 \mathrm{~m}$, dimly lighted by a $7 . \mathrm{W}$ light bulb.

The subject kinesthetically reproduced the perceived duration of each light by depressing a button mounted in the end of a small cylindrical case held in the hand. The duration of each response was measured electronically to the nearest millisecond. The response button did not operate the light, and since care was taken to minimize or eliminate any auditory cues that pressing and releasing the button might provide, the subject's reproduction of a time interval was entirely kinesthetic.

Procedure. The experimental design was a 5 by 5 repeatedmeasures Latin square. Each row was a sequence of the following inspection durations: $200,400,600,800$, and $1,000 \mathrm{msec}$. Three subjects were assigned to each row of the square, and each subject received all five inspection durations. Test measurements were made after each 1 -min inspection period, and there was a 1 -min rest between the conclusion of each test and the beginning of the next inspection. The columns of the Latin square represented the temporal order of the five inspection periods.

Preinspection measures were made for control purposes before the first inspection period, and practice trials were given before the preinspection measurements were made. Each subject was instructed to reproduce as carefully and accurately as possible the duration-the length-of each light. Shortly before each trial, the experimenter gave a warning signal by saying "Ready." The subject was instructed always to look at the light upon hearing the ready signal and, after the termination of the light, to hold the response button down just as long as the light had remained on. Preinspection measures were made using durations of 500,600 , and $700 \mathrm{msec}$. A set of preinspection measures consisted of five presentations of a particular duration at 3-sec intervals. A ready signal was given before each set, and the subject reproduced each duration just after it was presented. A block of preinspection measures consisted of three sets, each set using one of the above durations. Two blocks of preinspection measures were made, each block in an individually randomized order, and two additional blocks were counterbalanced in the reverse of that order. In all, 12 sets of preinspection measurements were made, and each of the above intervals was used in two of those sets.

Inspection periods were 1 min long, and, during each period, inspection lights of a single particular duration alternated with blank intervals of equal length. After each inspection period, a ready signal preceded a set of five 600 -msec test lights. The subject responded to the test lights in the same way as to the control lights.

Before the data were completely analyzed, each subject's preinspection measures were examined for nonmonotonicity. For example, a set of measures would be nonmonotonic if the mean response to the $500-\mathrm{msec}$ light were longer than the response to the 600 - or 700 -msec light. In the interest of reducing error variance, one subject having nonmonotonic preinspection measures was replaced. Four other subjects were replaced because they failed to respond to some stimuli or responded when no stimulus had been presented.

\section{Results and Discussion}

Preinspection measures. Figure $1 \mathrm{~A}$ shows the mean of the preinspection measures (open circles) at each level of duration. The means and variances of those measures were correlated, which would be expected if Weber's law holds in the domain of time perception. Thus, the preinspection measures were trans- 


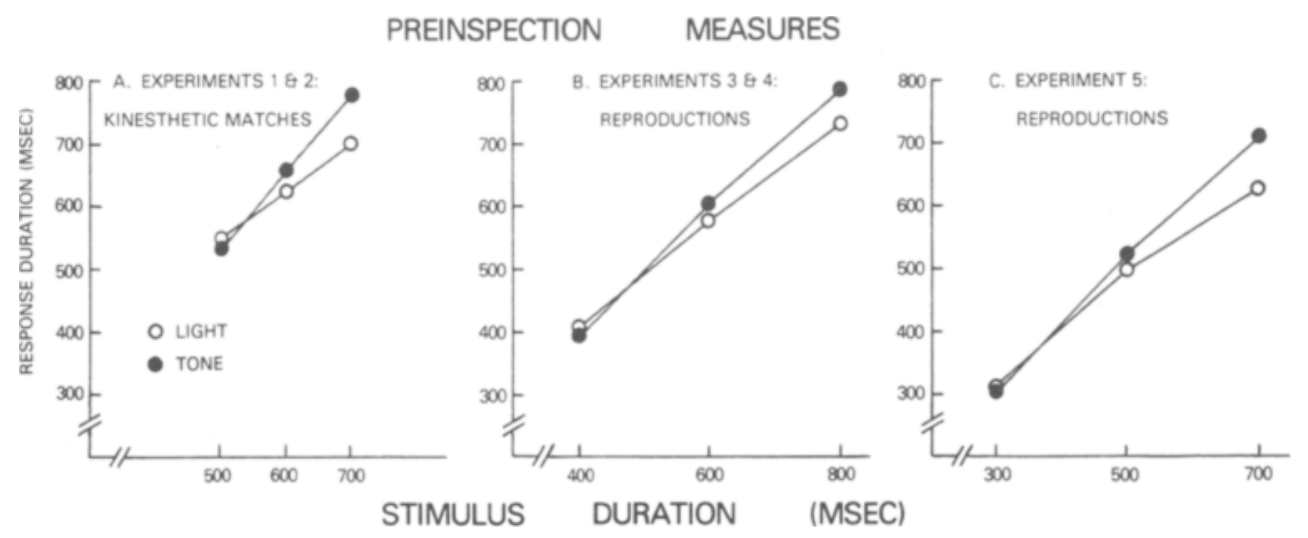

Figure 1. Perceived duration of preinspection measures. (A) Kinesthetic matching of lights (open circles) in Experiment 1 and tones (filled circles) in Experiment 2. (B) Reproduction of lights in Experiment 3 and tones in Experiment 4. (C) Reproductions of lights and tones in Experiment 5; repeated measures in both modalities.

formed logarithmically before performing an analysis of variance. A repeated-measures analysis of variance showed a highly significant linear trend $[F(1,28)=$ $119.66, \mathrm{p}<.001]$ accounting for $81.02 \%$ of the withinsubjects variance, and there was no significant quadratic trend $(F<1)$. Those results serve to validate the measurement procedure, to the extent that the subject's responses are an increasing monotonic function of the objective stimulus intervals.

Aftereffect measures. For each subject, the mean of all the preinspection measures was subtracted as a control from the mean of the test measures after each inspection duration, and those differences were expressed as percentages of the mean preinspection measure. The resulting aftereffect scores were given a positive sign when the test measure was greater than the preinspection control measure and a negative sign when the test measure was smaller. The mean of all the preinspection responses-to stimuli of 500,600 , and $700 \mathrm{msec}$ - was used as a control, rather than the response to the $600-\mathrm{msec}$ duration alone, in order to reduce the variability of the control measures. Since the relationship between responses and stimulus durations was almost perfectly linear (see Figure 1A), and since the mean of the objective durations of the preinspection stimuli was $600 \mathrm{msec}$, the above procedure is tantamount to solving a linear regression equation for the predicted value of the response to a 600 -msec stimulus and then using that predicted value as a control measure. That procedure makes it possible to take all of the preinspection responses into account in devising a control measure.

The results are shown in Figure $2 \mathrm{~A}$ (open circles) and in Table 1. A 5 by 5 repeated-measures Latinsquare analysis of variance was carried out (Winer, 1971, Plan 5). The sequence of inspection durations was a between-subjects factor in that analysis, and the temporal order of inspections and the duration of inspection periods were within-subjects factors. There was no significant effect of sequence $(F<1)$.
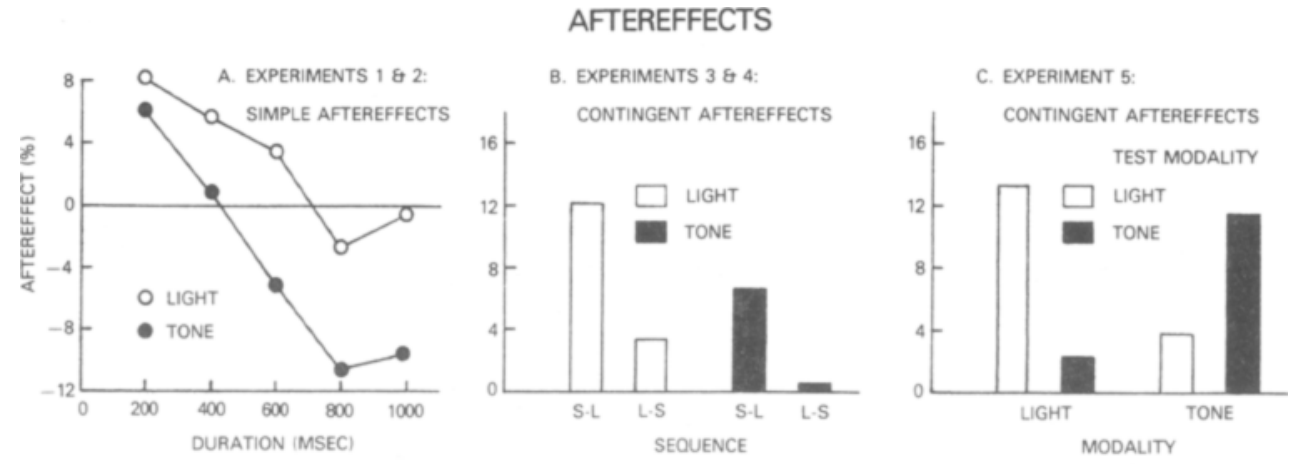

INSPECTION CONDITION

Figure 2. Aftereffect measures. (A) Simple aftereffects in vision (open circles) in Experiment 1 and in audition (filled circles) in Experiment 2; kinesthetic matching of test intervals in both experiments. (B) Contingent aftereffects in vision (open bars) in Experiment 3 and in audition (solid bars) in Experiment 4; reproduction of test light or tone. (C) Contingent aftereffects in Experiment 5; reproduction method; intramodal and cross-modal tests. 
Table 1

Simple Aftereffects: Mean Percentage Change in Perceived Durations of 600-Msec Test Intervals and $F$ Ratios for Linear Trends

\begin{tabular}{|c|c|c|c|c|c|c|c|}
\hline & \multicolumn{6}{|c|}{ Duration of Inspection } & \multirow{2}{*}{$\begin{array}{l}\text { Linear } \\
\text { Trend }\end{array}$} \\
\hline & 200 & 400 & 600 & 800 & 1000 & Combined & \\
\hline & \multicolumn{7}{|c|}{ Experiment 1 (Light Modality; $N=15$ ) } \\
\hline \multirow[t]{2}{*}{$\begin{array}{l}\text { Mean } \\
\text { SD }\end{array}$} & $\begin{array}{l}8.03^{* * *} \\
10.01\end{array}$ & $\begin{array}{r}5.42 \\
15.58\end{array}$ & $\begin{array}{l}3.61 \\
8.55\end{array}$ & $\begin{array}{r}-2.35 \\
9.85\end{array}$ & 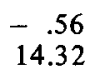 & $\begin{array}{l}4.09^{* *} \\
4.79\end{array}$ & $12.53 \dagger$ \\
\hline & \multicolumn{7}{|c|}{ Experiment 2 (Tone Modality; $\mathrm{N}=15$ ) } \\
\hline $\begin{array}{l}\text { Mean } \\
\text { SD }\end{array}$ & $\begin{array}{r}6.21 \\
15.19 \\
\end{array}$ & $\begin{array}{r}.91 \\
13.44 \\
\end{array}$ & $\begin{array}{r}-5.11 \\
13.81 \\
\end{array}$ & $\begin{array}{c}-10.44^{* *} \\
12.34 \\
\end{array}$ & $\begin{array}{l}-9.39^{*} \\
16.52 \\
\end{array}$ & $\begin{array}{l}6.74 \dagger \\
6.25 \\
\end{array}$ & $27.03 \dagger$ \\
\hline
\end{tabular}

Note-"Combined"= mean aftereffects across 200-, 400-, 800, and 1,000-msec inspections; changes in expected directions were made positive. $\quad{ }^{*} p<.05 . \quad{ }^{* *} p<.01 . \quad \neq p<.001$.

Since there was no significant Order by Duration interaction $(F<1)$, that interaction and the error within subjects were pooled. Using the resulting pooled error, there was no significant effect of temporal order $[F(4,52)=1.23, p>.25]$. The effect of inspection duration was significant $[F(4,52)=3.66, p<.05]$, there was a linear trend $[F(1,52)=12.53, p<.001]$ accounting for $85.63 \%$ of the variation due to that effect, and there was no significant deviation from linear trend $(F<1)$. The significant linear trend in Figure $1 \mathrm{~A}$ and Table 1 shows that inspection durations shorter than the 600 -msec test light tended to lengthen the perceived duration of the test and longer inspections tended to shorten its apparent duration. Thus, the direction of changes in the perceived duration of the test light indicates that the present aftereffect is a negative one, like most other aftereffects that have been measured to date.

Using the between-subjects standard deviations listed in Table 1, the mean aftereffect at each level of inspection duration was tested against zero. Only the 200-msec inspection duration produced an aftereffect that was significantly different from zero $[\mathrm{t}(14)=$ $3.11, \mathrm{p}<.01]$. No other inspection interval yielded a t value greater than 1.63 .

For each subject, aftereffects were combined across inspection durations of $200,400,800$, and $1,000 \mathrm{msec}$ by assigning a positive sign to any aftereffect in the expected direction-that is, to a lengthening of the perceived duration of the test light after inspections of 200 and $400 \mathrm{msec}$ and to a shortening after inspections of 800 and $1,000 \mathrm{msec}$. Since the expected direction of aftereffect cannot readily be determined for an inspection of $600 \mathrm{msec}$ - a duration equal to that of the test light-that duration was excluded from the present analysis. The combined aftereffect shown in Table 1 is significantly greater than zero $[t(14)=3.31, p<.01]$.

This experiment found a negative aftereffect of perceived duration in the visual modality that appears analogous to the temporal aftereffects that Huppert and Singer (1967) previously demonstrated in the auditory modality. The present aftereffect is also comparable in several respects to the other simple aftereffects described earlier in this paper, in that the perceived duration of a test interval was displaced in a direction away from the duration of the inspection stimulus.

\section{EXPERIMENT 2: SIMPLE AFTEREFFECTS IN AUDITION}

This experiment was designed to measure the effects of auditory inspections on the perceived duration of a $600-\mathrm{msec}$ test tone. In order to facilitate comparisons with the visual aftereffect found in Experiment 1 , the same inspection and test durations were used here, and the same experimental design was used, except for the substitution of tones for lights.

\section{Method}

Subjects. Fifteen male undergraduates were drawn from the same student population used earlier. Two potential subjects were replaced because of nonmonotonicity of their control measurements, as described in the procedure section of Experiment 1, and two others were replaced because they failed to respond to some of the stimuli.

Apparatus. The auditory stimuli consisted of $600-\mathrm{Hz}$ tones at $75 \mathrm{~dB}$ SPL delivered through a speaker located about $1.4 \mathrm{~m}$ in front of the subject. The experiment was conducted in the acoustic chamber described earlier. A 7-W light bulb provided dim illumination. The subjects kinesthetically reproduced the perceived duration of each tone by using the response button described earlier. The button did not produce the tone, and thus the subject's reproductions were entirely kinesthetic, as in Experiment 1.

Procedure. The same 5 by 5 Latin-square design was used as in Experiment 1, but a different randomized square was used here. The same inspection durations were used $-200,400,600,800$, and $1,000 \mathrm{msec}-$ and the same test duration- $-600 \mathrm{msec}$. All procedures were as nearly identical as possible to those used in Experiment 1 .

\section{Results and Discussion}

Preinspection measures. The means of those measures are shown in Figure 1A (filled cicles). Since the means and variances of the preinspection measures 
were correlated, as in Experiment 1, those measures were transformed logarithmically. A repeatedmeasures analysis of variance showed a highly significant linear trend $[F(1,28)=316.07, p<.001]$ accounting for $90.62 \%$ of the within-subjects variance, and a quadratic trend $[F(1,28)=4.72, p<.05]$ accounting for $1.35 \%$. Thus, as in Experiment 1 , the subject's responses were essentially an increasing linear function of the objective durations of the preinspection stimuli.

Figure 1A suggests that the preinspection responses to light and tone may differ initially - that is, before any aftereffects are produced. Although the present study primarily concerns aftereffects, possible preexisting differences between the perceived duration of light and tone may nevertheless be of interest. To assess any such preexisting differences, the log preinspection measures in Experiments 1 and 2 were entered into a 2 by 3 analysis of variance, in which the factors were modality (light, tone) and duration ( 500 , $600,700 \mathrm{msec}$ ). The modality variable was a betweensubjects factor, and there were repeated measures on the duration factor. There was no significant main effect of modality $(F<1)$, but there was a main effect of duration $[F(2,56)=205.29, p<.001]$ and a Modality by Duration interaction $[F(2,56)=9.87$, $\mathrm{p}<.001]$. The significant Modality by Duration interaction implies a difference between the slopes of the response to light and tone across the levels of duration, but none of the differences between light and tone were significant when those differences were tested separately at each duration [no $F(1,35)>3.54$, $\mathrm{p}<.10]$. The failure to find significant simple effects of modality after finding a significant Modality by Duration interaction may be due to the fact that the error term for the simple effects has a between-subjects component, while the interaction is a within-subjects effect (Winer, 1971).

Several earlier studies have found that tones appear longer than lights of equal duration for time intervals on the order of a second (e.g., Behar \& Bevan, 1961; Goldstone, Boardman, \& Lhamon, 1959; Goldstone \& Lhamon, 1971; Walker \& Scott, in press). To the extent that the present results show a significant tendency for tones to be perceived as longer than lights at the longer durations of 600 and $700 \mathrm{msec}$-as evidenced by the Modality by Duration interaction-these results are consistent with earlier findings.

Aftereffect measures. Individual aftereffect measures were found for each subject as in Experiment 1. The results are shown in Figure $2 \mathrm{~A}$ and in Table 1. A Latin-square analysis of variance was performed, in which the sequence of inspection intervals was a between-subjects factor and the temporal order of inspections and the duration of inspection intervals were within-subjects factors. There was no signif- icant effect of sequence $(F<1)$. There was no significant Order by Duration interaction $(F<1)$, so that interaction was pooled with the error within subjects. Using the pooled error, there was a significant effect of temporal order $[F(4,52)=2.64, p<.05]$ and a significant linear trend in that effect $[F(1,52)=$ $4.94, p<.05$ ] accounting for $46.71 \%$ of the variability due to temporal order, but there was no significant deviation from that linear trend $[F(3,52)=$ $1.88, p<.25]$. The linear trend in the temporal order effect was due to the tendency of the longer inspection intervals to produce larger negative aftereffect scoresthat is, greater apparent shortening of the test intervals-early in the sequence of repeated inspections, while the shorter inspection intervals tended to produce larger positive scores later in the sequence. There was a significant effect of inspection duration $[F(4,52)$ $=7.43, \mathrm{p}<.01]$, a highly significant linear trend $[F(1,52)=27.03, p<.001]$ accounting for $90.89 \%$ of the variation due to inspection duration, and no significant deviation from that linear trend $(F<1)$.

The linear trend in Figure 2A and Table 1 shows that inspection intervals shorter than the $600-\mathrm{msec}$ test tone tended to lengthen the perceived duration of the test and longer inspections tended to shorten its apparent duration, although the only aftereffects significantly different from zero were produced by the 800 - and $1,000 \mathrm{msec}$ inspections [values of $\mathrm{t}(14)$ were, respectively, 3.28 and 2.20 , and $\mathrm{p}$ values were $<.01$ and $<.05$ ]. No other inspection interval produced an aftereffect yielding a $t$ value greater than 1.58 .

The combined aftereffect score in Table 1 was found by the same procedure as in Experiment 1 . Here, also, the combined aftereffect, as expected, was significantly greater than zero $[\mathrm{t}(14)=4.18$, $\mathrm{p}<.001]$. There was no significant difference between the present combined auditory aftereffect and the combined visual aftereffect in the first experiment $[\mathrm{t}(28)=1.29]$.

The present aftereffect of perceived auditory duration is a negative aftereffect, like the earlier auditory aftereffect demonstrated by Huppert and Singer (1967). The visual aftereffect of perceived duration in Experiment 1 and the present auditory aftereffect both appear analogous in many respects to simple aftereffects in other modalities and domains.

\section{EXPERIMENT 3: CONTINGENT AFTEREFFECTS IN VISION}

Contingent aftereffects of perceived duration have been demonstrated previously in the auditory modality using a method of magnitude estimation (Walker \& Irion, 1979). In that study, after repeated presentations of a pair of inspection tones-the first short, 
and the second long-a pair of test tones of equal and intermediate length was presented. The first test tone then sounded longer than the second, and thus the perceived duration of each tone was contingent on its temporal order within the pair of test tones. Reversing the inspection tones, making the first long and the second short, produced a weaker contingent aftereffect that was significant under only one condition.

The present experiment was designed to assess the occurrences of contingent aftereffects of perceived duration in the visual modality. Short-long and longshort pairs of inspection lights were presented, and their effects on the perceived duration of intermediate test lights were measured using a reproduction method.

\section{Method}

Subjects. Twelve male undergraduate students were drawn from the same student population as in the first two experiments. One potential subject who failed to respond to some of the stimuli was replaced, and so was another who responded when no stimuli were present.

Apparatus. The same apparatus was used as in Experiment 1, and the experiment was conducted in the same acoustic chamber. The surface luminance of the neon light was $90 \mathrm{~mL}$, as in Experiment 1.

Procedure. In Experiments 1 and 2, inspection intervals of 200 and $800 \mathrm{msec}$ produced the largest simple aftereffects in the perceived duration of a $600-\mathrm{msec}$ test interval (see Figure 2A). For that reason, those inspection and test intervals were used in the present experiment. The experimental design was a 2 by 2 repeatedmeasures Latin-square. Each row was a sequence of the two inspection conditions: long-short $(800-200 \mathrm{msec})$, and short-long $(200-800 \mathrm{msec})$. Preinspection measurements were made before the first inspection, and test measurements were made after each inspection period.

The measurement method in the present experiment differs in an important respect from the kinesthetic reproduction method used in Experiments 1 and 2, since the response button turned on the light in the present experiment. After the presentation of a control or test light, the subject held the button down to produce a light matching the perceived duration of the presented interval. Now, suppose that a series of short-long inspection lights were to produce a contingent aftereffect resulting in the apparent lengthening of the first member of a pair of equal and intermediate test lights. Instead of presenting a pair of test lights, if a single test of intermediate duration were presented, and if the subject were instructed to produce immediately a response light matching the perceived duration of the test, then the subject should produce a response longer than the duration of the test light. In effect, the subject would still observe a pair of test lights under this procedure, but the subject himself would determine the duration of the second member of the pair. If the short-long inspection procedure made the first member of a test pair appear longer in relation to the second-through apparent lengthening of the first member or apparent shortening of the second, or through concurrent changes in the perceived duration of both members of the test pair-then the subject would increase the duration of the second light in order to match the perceived duration of the first. On the other hand, if the long-short inspection condition were to produce a contingent aftereffect of apparent lengthening of the second member of a test pair in relation to the first, then the subject should produce a response shorter than the duration of the intermediate test light.

For control purposes, 12 sets of preinspection measures were made using the same procedures as in Experiments 1 and 2, ex- cept here the response button turned on the light. Those measures were made using durations of 400,600 , and $800 \mathrm{msec}-\mathrm{a}$ wider range of intervals than was used in the earlier experiments-in the interest of providing the subjects with more readily discriminable stimuli. In the present experiment, no subject was replaced because of nonmonotonic preinspection measures, as defined in the procedure section of Experiment 1.

Inspection periods were $90 \mathrm{sec}$ long. Test measures were made after each of the two inspection periods. There was a 1 -min rest between the conclusion of the first test measurements and the beginning of the next inspection. The members of each pair of inspection lights were separated by a blank interval of $400 \mathrm{msec}$, and successive pairs were presented at $3-\mathrm{sec}$ intervals. Thus, there was a blank interval of $1,600 \mathrm{msec}$ between successive pairs. The inspection stimuli were clearly perceived as pairs of lights having a well-defined temporal order, long-short or short-long, as opposed to an unsegregated series of long and short intervals.

\section{Results and Discussion}

Preinspection measures. Figure $1 B$ shows the means of the preinspection measures (open circles). A repeated-measures analysis of variance of the log preinspection measures showed a linear trend $[F(1,22)=$ $736.35, \mathrm{p}<.001]$ accounting for $95.19 \%$ of the variance within subjects and a quadratic trend $[F(1,22)$ $=15.24, p<.001]$ accounting for $1.97 \%$ of the variance. Thus, the present reproduction method-in which the response button turned on the lightprovided reliable measures of the preinspection intervals.

Aftereffect measures. The mean of each subject's preinspection measures was subtracted as a control from the mean of the test measures after each period, and those differences were expressed as percentages of the control mean. The short-long inspection condition was expected to produce an increase in the test measures, due to apparent lengthening of the first member of a test pair in relation to the second, and the long-short condition was expected to produce a decrease, due to apparent shortening of the first member of a test pair in relation to the second.

Figure 2B and Table 2 shows the aftereffect measures. A 2 by 2 repeated-measures Latin-square analysis of variance was performed. The two sequences of inspection conditions (long-short followed by short-long, and short-long followed by long-short) comprised the rows of the Latin-square and constituted a between-subjects factor. The two inspection conditions (long-short, short-long) and the temporal order of inspections (first, second) were withinsubjects factors. There was no significant effect of inspection sequence $F(1,10)=1.44, p>.25$, but there was a significant effect of temporal order $[F(1,10)$ $=5.62, \mathrm{p}<.05]$. The first inspection condition to be presented, whether short-long or long-short, tended to produce stronger aftereffects in the expected direction. The second inspection tended to produce weaker aftereffects, often in a direction contrary to expectations. Thus, the temporal order effect represents a carryover of whichever aftereffect was produced by 
Table 2

Contingent Aftereffects: Mean Percentage Change in Perceived Duration of 600 -Msec Test Intervals

\begin{tabular}{lccc}
\hline & \multicolumn{3}{c}{ Order of Inspection Intervals } \\
\cline { 2 - 3 } & $\begin{array}{c}\text { Short-Long } \\
(200-800 \text { msec) }\end{array}$ & $\begin{array}{c}\text { Long-Short } \\
(800-200 \text { msec) }\end{array}$ & Combined \\
\hline Mean & Experiment & (Light Modality; $\mathrm{N}=12)$ \\
SD & $12.08^{* *}$ & 3.63 & $4.22^{*}$ \\
& 12.47 & 15.76 & 5.45 \\
Mean & Experiment & (Tone Modality; $\mathrm{N}=12)$ \\
SD & $6.78^{* *}$ & .76 & $3.01^{*}$ \\
\hline
\end{tabular}

Note-Long-short inspection produced apparent lengthening of test intervals, contrary to expectations.

$* p<.05 . \quad * * p<.01$.

the first inspection period. The effect of inspection condition was significant $[F(1,10)=10.22, p<.01]$.

Table 2 shows the mean aftereffects produced by both inspection conditions and the combined aftereffect. The short-long inspection produced a significant lengthening of the test measures $[t(11)=3.36$, $\mathrm{p}<.01]$. Contrary to expectations, the long-short inspection condition also produced a lengthening of the test measures-very likely due to the temporal order effect described above-but that lengthening was not significantly different from zero $[t(11)=.80]$. Aftereffects were combined for individual subjects across both inspection conditions by assigning positive signs to those in the expected direction. The combined aftereffect was significantly greater than zero $[\mathrm{t}(11)=2.68, \mathrm{p}<.05]$.

The contingent aftereffect of perceived duration found in the present experiment represents a new phenomenon in the visual modality. The perceived duration of a test light depends on its temporal orderfirst or second-within a pair of lights and also depends on the prior presentation of short-long inspection lights; thus, the present aftereffect can be described as an order-contingent aftereffect of perceived duration. This visual aftereffect is comparable to the order-contingent duration aftereffect previously found in the auditory modality (Walker \& Irion, 1979). The present aftereffect also appears analogous, in a formal sense, to the McCollough effect and other contingent aftereffects.

\section{EXPERIMENT 4: CONTINGENT AFTEREFFECTS IN AUDITION}

The results of the present experiment, taken with the earlier results of Experiment 3, provide a basis for comparing contingent aftereffects in vision and audition. The present experiment also essentially replicates the earlier order-contingent aftereffect of Walker \& Irion (1979), although a different measurement method was used here.

\section{Method}

Subjects. Twelve male undergraduates served as subjects. Three subjects were replaced because of their failure to follow instructions.

Apparatus. The same apparatus was used as in Experiment 2, and also the same frequency and intensity of tone, $600 \mathrm{~Hz}$ at $75 \mathrm{~dB}$ SPL.

Procedure. The experimental design was a 2 by 2 repeatedmeasures Latin-square, as in Experiment 3. Procedures were the same as in that earlier experiment, except for the present use of tones instead of lights. The response button turned on the tone, and the subject held the button down to produce a tone matching the perceived duration of a control or test tone. Preinspection measures were made using intervals of 400,600 , and $800 \mathrm{msec}$. The test interval was $600 \mathrm{msec}$. The two inspection conditions were long-short ( $800-200 \mathrm{msec})$ and short-long (200-800 msec). Like the inspection lights in Experiment 3, the present inspection tones were clearly perceived as pairs of intervals, as opposed to an unsegregated series of long and short tones.

\section{Results and Discussion}

Preinspection measures. The means of those measures are shown in Figure 1B (filled circles). The log preinspection measures showed a linear trend in a repeated-measures analysis of variance $[\mathrm{F}(1,22)=$ $1,272.65, \mathrm{p}<.001]$ accounting for $96.77 \%$ of the variance within subjects and a quadratic trend $[F(1,22)$ $=20.49, \mathrm{p}<.001]$ accounting for $1.56 \%$ of the variance.

Figure 1B, like Figure 1A, suggests that there may be differences between the preinspection responses to light and to tone-that is, differences between the perceived duration of time intervals in those modalities before the induction of any aftereffects. Thus, the log preinspection measures in Experiments 3 and 4 were entered into a 2 by 3 analysis of variance. The factors were modality (light, tone) and duration ( 400 , $600,800 \mathrm{msec}$ ); there were repeated measures on the latter factor. There was no significant main effect of modality $(F<1)$, but there was a main effect of duration $[\mathrm{F}(2,44)=990.07, \mathrm{p}<.001]$ and a Modality by Duration interaction $[F(2,44)=8.16, p<.001]$. Thus, there was a significant difference between the slopes of the response to light and to tone across durations, but there was no significant difference between light and tone tested at each of the three levels of duration [no $\mathrm{F}(1,32)>4.07, \mathrm{p}<.10$ ]. Thus, the pattern of differences between responses to light and tone in Experiments 3 and 4 is comparable to the pattern observed earlier in Experiments 1 and 2. The degrees of freedom for the error term for the preceding tests of simple effects are a function of the magnitudes of the errors within and between subjects and thus differ from the degrees of freedom in the analogous tests in Experiments 1 and 2. The failure to find significant simple effects of modality after finding a significant Modality by Duration interaction may be due to the fact that the simple effects involve between-subjects components, while the interaction is a within-subjects effect. Thus, the pattern of differences between the preinspection responses to 
light and tone in Experiments 3 and 4 is comparable to the pattern observed in Experiments 1 and 2, even though the latter experiments utilized a different reproduction method.

Aftereffect measures. The aftereffect measures shown in Figure $2 \mathrm{~B}$ and in Table 2 were found by the same procedures used in the earlier experiments. A 2 by 2 repeated-measures Latin-square analysis of variance was performed, in which the two sequences of inspection conditions (long-short followed by short-long and short-long followed by long-short) constituted a between-subjects factor. The two inspection conditions (long-short, short-long) and the temporal order of inspections (first, second) were within-subjects factors. There was no significant effect of sequence $(F<1)$ or temporal order $[F(1,10)$ $=1.14, p<.25$, but there was a significant effect of inspection condition $[F(1,10)=7.26, p<.05]$.

Table 2 shows the aftereffects produced by both inspection conditions and the combined aftereffect. As expected, the short-long inspection condition produced a significant lengthening of the test measures $[t(11)=4.74, p<.01]$, but the long-short inspection also produced a slight, although not significant, lengthening $[t(11)=.28]$. Aftereffects were combined across both inspection conditions, as in Experiment 3, and the combined aftereffect was significantly greater than zero $[t(11)=2.68, p<.05]$. The $t$ values for the combined aftereffects in this experiment and in Experiment 3 are identical to two decimal places.

The contingent auditory aftereffect in the present experiment appears substantially smaller than the contingent visual aftereffect in the preceding experiment, but neither the aftereffects produced by the short-long inspection nor the combined aftereffects differed significantly between modalities [neither $t(22)>1.37$ ]. In both modalities, vision and audition, only the short-long inspection condition produced a significant aftereffect. In that respect, the present results are largely consistent with the ordercontingent auditory aftereffect described earlier by Walker and Irion (1979), in which the aftereffects produced by long-short inspections $(1,000-200 \mathrm{msec})$ were weak or absent.

\section{EXPERIMENT 5: CONTINGENT AFTEREFFECTS WITHIN AND BETWEEN MODALITIES}

When analogous phenomena can be produced in different modalities, such as simple and contingent aftereffects in vision and audition, the question of possible transfer across modalities arises. Would a visual inspection produce an auditory aftereffect, and would there be any transfer in the other direction? Jaffe (1956) reported a figural aftereffect of apparent size that transferred from vision to kinesthe- sis, and Mayer (1961) reported cross-modal transfer of a curvature aftereffect between those modalities in that direction, but Day and Singer (1964) found no evidence of transfer of a tilt aftereffect between vision and touch in either direction.

In the domain of time perception, cross-modal anchor effects have been demonstrated involving vision and audition, in which a long or short anchor in one modality influenced the subsequent judgment of time intervals in the other modality (e.g., Behar \& Bevan, 1961; Goldstone \& Lhamon, 1971). To the extent that an anchor effect may be a species of simple aftereffect, those studies may have demonstrated cross-modal transfer of simple aftereffects of perceived duration between vision and audition.

The present experiment was designed to test the possibility of cross-modal transfer of contingent aftereffects. The effects of visual inspections on visual and auditory tests and the effects of auditory inspections on tests in both modalities were measured using a reproduction method. Only the short-long inspection condition was used in the present experiment.

\section{Method}

Subjects. Thirty-two male undergraduates participated. Twelve subjects were replaced because they failed to respond to some stimuli or because they pressed the response button when no stimulus had been presented. One subject was replaced because he was deaf in one ear. All other subjects claimed to be free of serious problems in vision or hearing. No subject's preinspection measures were nonmonotonic, as described in the Procedure section of Experiment 1.

Apparatus. The same apparatus and the same intensities of light and tone were used as in the experiments described previously. The neon light assembly rested on the top of the speaker enclosure about $1.4 \mathrm{~m}$ in front of the subject. The surface luminance of the light was about $90 \mathrm{~mL}$. Tones were presented at $600 \mathrm{~Hz}$ and at an intensity of $75 \mathrm{~dB}$ SPL by using one channel of a stereo tape recorder. Audio signals on the other channel of the tape recorder controlled the presentation of the light by means of an electronic trigger. To eliminate any cross-talk between channels, when one channel was delivering a stimulus, the other was disconnected. Preinspection durations were 300,500 , and $700 \mathrm{msec}$, and the test duration was $500 \mathrm{msec}$ After the experiment, those durations were measured electronically, as reproduced by the tape recorder; the mean duration was $3.25 \%$ greater than nominal, and the standard deviation of the difference between observed and nominal measures was $1.36 \%$. The response button turned on the light or the tone, as in Experiment 3 or Experiment 4.

Procedure. The subjects were divided into two groups, one of which received only light inspections and the other only tone inspections, but test measurements were made in both modalities in both groups. The experimental design thus makes it possible to assess the transfer of contingent aftereffects between vision and audition and to compare any such cross-modal aftereffects with contingent aftereffects occurring within those modalities.

Preinspection lights and tones were presented in sets of five at 3-sec intervals. Each subject responded to six sets of lights and six sets of tones-a total of 12 sets of preinspection measures-in TLLT order. Durations were counterbalanced within subjects so that each interval-300,500,700 msec-was used in two sets of preinspection measures. The same counterbalanced order was used for all subjects. 
The inspection stimuli were short-long pairs of lights or tones, 200-1,000 msec, presented at 3-sec intervals. After a $90-\mathrm{sec}$ inspection period, each subject was given a set of five test stimulilights or tones-followed by another test set in the other modality presented as soon as possible. Half the subjects in the lightinspection group were tested first with light and then with tone, and half were tested in the reverse order; the subjects in the toneinspection group were treated analogously.

\section{Results and Discussion}

Preinspection measures. Figure $1 \mathrm{C}$ shows the mean preinspection measures for light (open circles) and for tone (closed circles). The log measures were subjected to a 2 by 3 analysis of variance, in which the factors were modality (light, tone) and duration $(300,500,700 \mathrm{msec})$, both factors representing repeated measures. There were significant main effects of modality and duration $[F(1,31)=13.70, p<.001$; and $F(2,62)=1,594.54, p<.001]$ and a significant Modality by Duration interaction $[F(2,62)=18.19$, $\mathrm{p}<.001]$. The simple effect of duration was highly significant for light $[F(2,155)=547.25, p<.001]$; within that simple effect, a linear trend $[F(1,155)=$ $1,057.80, \mathrm{p}<.001]$ accounted for $96.65 \%$ of the variation and a quadratic trend $[F(1,155)=36.71$, $p<.001]$ accounted for $3.35 \%$. The simple effect of duration was also significant for tone $[F(2,155)=$ $805.21, p<.001]$; within that simple effect, a linear trend $[F(1,155)=1,572.54, p<.001]$ accounted for $97.65 \%$ of the variation and a quadratic trend $[F(1,155)$ $=37.89, p<.001]$ accounted for $2.35 \%$. There was no significant difference between modalities at a duration of $300 \mathrm{msec}(\mathrm{F}<1)$, but differences were significant at 500 and $700 \mathrm{msec}[\mathrm{F}(1,155)=9.11, \mathrm{p}<.01$; and $F(1,155)=42.24, p<.001]$. The present results show that tones were perceived as longer than lights at the longer preinspection durations, consistent with earlier studies (e.g., Goldstone et al., 1959) and with trends in other experiments in the present study.

Aftereffect measures. A visual aftereffect score was found for each subject by subtracting the mean of the preinspection responses to light from the mean responses to the test lights and expressing the difference as a percentage of the preinspection mean. An auditory aftereffect score was found analogously. Figure $2 \mathrm{C}$ and Table 3 show the mean visual and auditory aftereffects. After a visual inspection, a visual aftereffect is an intramodal effect and an auditory aftereffect-if any-is a cross-modal effect; after an auditory inspection, an auditory aftereffect is intramodal and a visual aftereffect would be cross-modal.

Aftereffect scores were subjected to a 2 by 2 Latinsquare analysis of variance (Winer, 1971, Plan 9). The rows of the Latin-square were the two sequences of test modalities (light-tone, tone-light); the columns were the temporal order of the tests (first, second); and the square was replicated for each inspection modality (light, tone). There were repeated measures within the rows of each square, but the inspection modalities and the sequences of test modalities constituted between-subjects factors. There was no main effect of inspection modality or sequence of test modalities, nor was there any interaction between those factors (all Fs $<1$ ). Within subjects, there was no effect of temporal order or test modality (both Fs $<1$ ) or any significant interaction between those factors $[F(1,28)=2.01, p<.25]$, but there was a significant Inspection Modality by Test Modality interaction $[F(1,28)=8.43, p<.01]$. Figure $2 \mathrm{C}$ shows the nature of that interaction: Intramodal aftereffects appear much larger than cross-modal aftereffects. After a visual inspection, a visual test showed a significant intramodal aftereffect $[\mathrm{t}(15)=3.37, \mathrm{p}<.01]$, but an auditory test showed no significant crossmodal aftereffect $[t(15)=1.11]$. Analogously, after an auditory inspection, an auditory test showed a significant intramodal aftereffect $[\mathrm{t}(15)=3.31, \mathrm{p}<.01]$, but a visual test showed no significant cross-modal aftereffect $[t(15)=1.14]$. The combined intramodal aftereffects were significantly greater than zero [ $t(31)$ $=4.78, \mathrm{p}<.001]$, but the combined cross-modal aftereffects were not $[t(31)=1.58]$.

The present experiment found significant contingent aftereffects of perceived duration within the visual and auditory modalities but no significant transfer of aftereffects between modalities. It is, of course, possible that cross-modal aftereffects might be produced by different experimental procedures, perhaps by longer inspection periods or by using different intervals of time. But in the light of the present results, any contingent aftereffects occurring between vision

Table 3

Contingent Aftereffects Within Vision and Audition and Test of Cross-Modal Effects: Mean Percentage Change in Perceived Duration of 500-Msec Test Intervals (Experiment 5)

\begin{tabular}{|c|c|c|c|c|c|c|c|c|c|c|c|}
\hline \multicolumn{8}{|c|}{ Inspection Modality } & & & & \\
\hline \multicolumn{4}{|c|}{ Light $(\mathrm{N}=16)$} & \multicolumn{4}{|c|}{ Tone $(N=16)$} & \multicolumn{4}{|c|}{ Combined Aftereffects } \\
\hline \multicolumn{2}{|c|}{ Light Test } & \multicolumn{2}{|c|}{ Tone Test } & \multicolumn{2}{|c|}{ Light Test } & \multicolumn{2}{|c|}{ Tone Test } & \multicolumn{2}{|c|}{ Intramodal } & \multicolumn{2}{|c|}{ Cross-Modal } \\
\hline Mean & SD & Mean & SD & Mean & SD & Mean & SD & Mean & SD & Mean & SD \\
\hline $13.34 *$ & 15.83 & 2.35 & 8.44 & 3.87 & 13.58 & $11.42^{*}$ & 13.80 & $12.38 * *$ & 14.64 & 3.11 & 11.15 \\
\hline
\end{tabular}

Note-Intramodal combined results = light inspection and test, tone inspection and test. Cross-modal combined results $=$ light inspection, tone test; tone inspection, light test. $\quad{ }^{*} p<.01 . \quad{ }^{* *} p<.001$. 
and audition can be expected to be considerably smaller than contingent aftereffects within those modalities-at least under conditions approximating those of the present experiment.

\section{GENERAL DISCUSSION}

In considering the inspection procedures in the simple-aftereffect experiments, it must be recognized that some confounding is unavoidable. During each inspection period, lights or tones of a particular duration alternated with blank intervals of equal length. Thus, for all levels of duration, the inspection periods were half-filled and half-empty. But the inspection periods were all the same length, and thus the number of inspection stimuli was confounded with their duration, since there were fewer longer stimuli in an inspection period of constant length. If the number of stimuli had been equated across inspection periods, then the total length of inspection-and the length of exposure to intervals filled with light or tone-would have been confounded with duration. Indeed, some kind of confounding is inevitable in any experiment utilizing multiple presentations of different inspection durations. However, it appears implausible for several reasons to attribute the present aftereffects solely to the number of inspection stimuli, as opposed to their duration. Previous studies of anchor effects have shown that a short anchor lengthens the perceived duration of a subsequently presented series of time intervals and a long anchor shortens their perceived duration (e.g., Behar \& Bevan, 1961; Goldstone et al., 1959). To the extent that those anchor effects represent a species of negative aftereffect, the present aftereffects of perceived duration are consistent with those earlier results. Furthermore, the simple and contingent aftereffects in the present study are consistent with each other, in that both kinds of phenomena are negative aftereffects. In the contingent aftereffects, the confounding described above does not occur, since the same number of inspection stimuli were presented in both the short-long and long-short conditions. Thus, the contingent aftereffects are clearly attributable to the duration and temporal order of inspection stimuli and not to the number of lights or tones occurring in an inspection period.

The simple aftereffects of perceived duration described in the present study are consistent with models of neural adaptation that have been proposed to account for other simple aftereffects (Day \& Singer, 1969; Osgood \& Heyer, 1952; Sekuler \& Pantle, 1967). Extending such a model to the present simple aftereffects, suppose there are duration detectors in the auditory system, each responsive to a range of time intervals. Now, suppose that each detector is maximally sensitive to a particular duration and less responsive to durations that are farther away from its region of peak sensitivity. Furthermore, suppose that the perceived duration of a sound is determined by the particular detector showing the greatest response. Adapting a set of such detectors to a long inspection tone would displace the perceived duration of a subsequently presented intermediate test tone toward the short end of the duration dimension. Analogously, a short inspection tone would displace an intermediate test toward the long end of the duration dimension. Thus, both inspection stimuli-long and shortwould produce negative aftereffects. In the visual system, duration detectors functioning in a similar manner would account for simple aftereffects of perceived duration in the visual modality.

A neural adaptation model has also been proposed to account for the McCollough effect (McCollough, 1965). If there were orientation-specific edge detectors in the visual system, color-coded in an opponentprocess manner, then adapting such detectors to gratings differing in orientation and color would produce color aftereffects contingent on the orientation of achromatic test gratings. A few such color-coded orientation detectors, such as McCollough proposed, were later found in the visual cortex of the monkey (Hubel \& Wiesel, 1968). Applying a neural adaptation model to the present contingent aftereffects, suppose there are duration detectors in the auditory and visual systems that are also sensitive to temporal order in a sequence of stimuli. Adapting such detectors to a series of pairs of inspection intervals, the first short and the second long, would produce a contingent aftereffect of perceived duration in a subsequently presented pair of intermediate test intervalsthat is, the first test would appear longer than the second. Analogously, a series of long-short inspection intervals would make the first member of an intermediate test pair appear shorter than the second.

The results of the present experiments are only halfconsistent with the neural adaptation model proposed above, since only the short-long inspection condition produced significant contingent aftereffects, while the long-short condition produced none. In that respect, the present results are largely consistent with the earlier study of Walker and Irion (1979), in which the long-short inspection condition produced only a weak auditory aftereffect under one condition. There is no obvious reason why only the short-long condition should produce a significant aftereffect or produce a greater aftereffect than the other condition. It is as though the McCollough effect could be produced by green horizontal and red vertical gratings, but not by interchanging those pairings of colors and orientations. The observed asymmetry of the short-long and long-short inspections, in terms of their effectiveness, remains a puzzle.

Several workers have criticized the neural adaptation model of the McCollough effect, largely on the grounds of the very long persistence of that after- 
effect (e.g., Jones \& Holding, 1975). An alternative model has been proposed, based on classical conditioning (Leppman, 1973; Murch, 1972, 1976; Skowbo, Timney, Gentry, \& Morant, 1975). The orientation of a grating is considered to be a conditional stimulus, and the color is considered an unconditioned stimulus. However, the conditioned color response elicited by each orientation of the achromatic test grating is essentially the complement of the color paired with that orientation during the inspection period. Thus, there is a difficulty in applying a classical conditioning model to the McCollough effect or to any contingent aftereffect, as some of the present writers have argued earlier (Walker, 1977; Walker \& Irion, 1979).

Setting aside the above difficulty inherent in the conditioning model and assuming that complementary responses do somehow become conditioned in the McCollough effect, the classical conditioning model can be extended to the present contingent aftereffects. Here, the conditioned stimulus is the temporal order of a light or tone-first or secondwithin a pair of inspection intervals, and the unconditioned stimulus is the duration of the interval-long or short. After the repeated pairing of the first temporal order with a short duration and the second order with a long duration, a test interval of intermediate duration should appear longer when it is the first member of a test pair and shorter when it is the second member. The results of the present study are consistent with that expectation, but no significant aftereffects occurred when long-short inspection intervals were used. There is no obvious reason why one pairing of temporal order and duration, but not the other, should produce an aftereffect. Thus, the classical conditioning model fares no better than the neural adaptation model in explaining the observed asymmetry of the short-long and long-short inspection conditions.

There are great similarities between the perception of time in vision and audition and in other modalities as well. Thus, it is tempting to suppose that there may exist a single mechanism for time perception, an amodal mechanism assessing the duration of events independently of their modality of occurrence. Such a mechanism would readily account for cross-modal matching and comparison of time intervals, as in Experiments 1 and 2 , in which the subjects kinesthetically reproduced the perceived duration of lights and tones. A single mechanism would also help account for the similarity between the simple and contingent aftereffects observed in vision and audition, but the absence of significant cross-modal contingent aftereffects argues against such a mechanism.

The hypothesis of a single mechanism of perceived duration presents yet another difficulty. In Experiment 5 , tones were perceived as longer than lights in the preinspection measures, and there were significant Modality by Duration interactions in the experiments described earlier (see Figure 1). Those results are consistent with previous findings (Goldstone et al., 1959; Walker \& Scott, in press). Thus, the perception of duration cannot take place wholly within a single mechanism. Separate timekeeping processes must take place within vision and audition-at least to the extent that the auditory clock appears to run faster than the visual clock. Other workers have previously reached similar conclusions (Goldstone \& Lhamon, 1971).

While there is evidence of separate timekeeping processes in vision and audition, simple and contingent aftereffects of perceived duration are very similar in those modalities. Furthermore, those aftereffects are analogous in many respects to simple and contingent aftereffects in other modalities involving other sensory dimensions such as color, size, and orientation.

\section{REFERENCES}

Allan, L. G. The perception of time. Perception \& Psychophysics, $1979,26,340-354$.

Behar, I., \& BeVAn, W. The perceived duration of auditory and visual intervals: Cross-modal comparison and interaction. American Journal of Psychology, 1961, 74, 12-26.

DAY, R. H., \& Singer, G. Spatial aftereffects within and between kinesthesis and vision. Journal of Experimental Psychology, $1964,68,337-343$.

DAy, R. H., \& Singer, G. Issues in the explanation of sensory adaptation and aftereffect. In Arvo Lehtovaara (Ed.), Contemporary research in psychology of perception, in honorem Kai von Fieandt sexagenarii. Porvoo, Finland: Shoderstrhom, 1969.

Favreau, O. E., Emerson, V. R., \& Corballis, M. C. Motion perception: A color-contingent aftereffect. Science, 1972, 176, 78-79.

Fraisse, P. [The psychology of time] (J. Leith, trans.). New York: Harper \& Row, 1963. (Originally published, 1963.)

Gibson, J. J., \& RADner, M. Adaptation, after-effect, and contrast in the perception of tilted lines. I. Quantitative studies. Journal of Experimental Psychology, 1937, 20, 453-467.

Goldstone, S., Boardman, W. K., \& Lhamon, W. T. Intersensory comparisons of temporal judgments. Journal of Experimental Psychology, 1959, 57, 243-248.

Goldstone, S., \& Lhamon, W. T. Levels of cognitive functioning and the auditory-visual difference in human timing behavior. In M. H. Appley (Ed.), Adaptation-level theory: A symposium. New York: Academic Press, 1971.

HELD, R., \& ShatTuck, S. Color- and edge-sensitive channels in the human visual system: Tuning for orientation. Science, 1971, 174, 314-316.

Hepler, N. Color: A motion-contingent aftereffect. Science, 1968, 162, 376-377.

Hubel, D. H., \& Wiesel, T. N. Receptive fields and functional architecture of monkey striate cortex. Journal of Physiology, $1968,195,215-243$.

Huppert, F., \& Singer, G. An aftereffect in judgment of auditory duration. Perception \& Psychophysics, 1967, 2, 544-546.

JAFFE, R. The influence of visual stimulation on kinesthetic figural after-effects. American Journal of Psychology, 1956, 69, 70-75. 
Köhler, W.. \& Dinnerstein, D. Figural aftereffects in kinesthesis. In Miscellanea psychologica: Albert Michotte. Louvain, Belgium: University of Louvain, 1947.

Köhler, W., \& W'̈́lach, H. Figural after-effects: An investigation of visual processes. Proceedings of the American Philosophical Society, 1944, 88, 269-357.

Leppmann, P. K. Spatial frequency dependent chromatic aftereffects. Nature, 1973, 242, 411-412.

MAYER, J. Influence of inspection of a visually curved field on kinesthetic figural after-effects. Perceptual and Motor Skills, $1961,13,13-14$.

Mayhew, J. E. W., \& Anstis, S. M. Movement aftereffects contingent on color, intensity, and pattern. Perception \& Psychophysics, 1972, 12, 77-85.

McCollough, C. Color adaptation of edge-detectors in the human visual system. Science, 1965, 149, 1115-1116.

Murch, G. M. Binocular relationships in a size and color orientation specific aftereffect. Journal of Experimental Psychology, $1972,93,30-34$.

Murch, G. M. Classical conditioning of the McCollough effect: Temporal parameters. Vision Research, 1976, 16, 615-619.

Osgood, C. E., \& HEYER, A. W. A new interpretation of figural aftereffects. Psychological Review, 1952, 59, 98-118.
Sekuler, R., \& Pantle, A. A model for aftereffects of seen movement. Vision Research, 1967, 7, 427-439.

Skowbo, D., Timney, B. N., Gentry, T. A., \& Morant, R. B. McCollough effects: Experimental findings and theoretical accounts. Psychological Bulletin, 1975, 82, 497-510.

WALKER, J. T. A texture-contingent visual motion aftereffect. Psychonomic Science, 1972, 28, 563-570.

WALKER, J. T. Orientation-contingent tactual size aftereffects. Perception \& Psychophysics, 1977, 22, 563-570.

WALKER, J. T. Simple and contingent aftereffects in the kinesthetic perception of length. Journal of Experimental Psychology. Human Perception and Performance, 1978, 4, 294-301.

Walker, J. T., \& Irion, A. L. Two new contingent aftereffects: Perceived auditory duration contingent on pitch and on temporal order. Perception \& Psychophysics, 1979, 26, 241-244.

WINER, B. J. Statistical principles in experimental design (2nd ed.). New York: McGraw-Hill, 1971.

Woodrow, H. Time perception. In S. S. Stevens (Ed.), Handbook of experimental psychology. New York: Wiley, 1951.

(Received for publication September 29, 1980; revision accepted March 20, 1981.) 